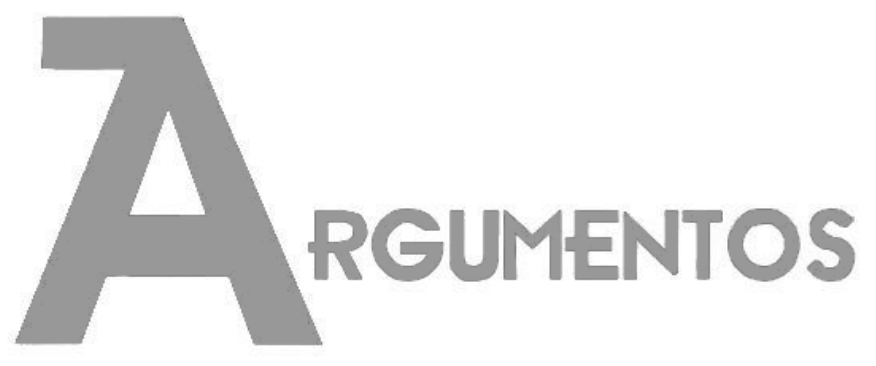

Vol. 17, n. 1, jan./jun. 2020 ISSN: 2527-2551 (online)

https://www.periodicos.unimontes.br/index.php/argumentos

\title{
Dinâmicas territoriais e saber local em torno de conflitos em um bairro atingido pelo desastre de 2011 em Nova Friburgo (RJ)
}

\author{
Maria Suellen Timoteo Correa ${ }^{1}$
}

Recebido em: 06/10/2019

Aprovado em: 22/12/2019

\begin{abstract}
Resumo: A presente análise trata de formas em que a participação social e política pela reconstrução de espaços atingidos por catástrofes de chuvas podem repercutir nas transformações da relação do Poder Público com comunidades e nas políticas públicas urbanas. Pretende-se apresentar o saber local presente nas disputas territoriais e no acesso a espaços técnicos e a políticas públicas de gestão de desastre e de planejamento urbano. Para tanto, é apresentada parte da minha pesquisa de mestrado, envolvendo o estudo de caso da participação política de moradores do bairro Córrego D'Antas, em Nova Friburgo (RJ), em prol da reconstrução da localidade e de melhorias nos serviços, após terem sido atingidos pelo desastre envolvendo chuvas, enchentes e deslizamentos de terra em janeiro em 2011. Serão aprofundados casos ligados a algumas obras e reuniões de revisão do Plano Diretor no bairro, em 2014, no contexto pós-desastre. A participação através da Associação de Moradores do bairro e o acionamento de novos saberes na esfera política são tomados como exemplo neste artigo, de forma a trazer reflexões sobre a afirmação de territorialidades em contextos de desastres urbanos.
\end{abstract}

Palavras-chave: Desastres. Dinâmicas Territoriais. Participação Comunitária. Saber Local.

\section{Dinámica territorial y conocimiento local sobre conflictos en un barrio afectado por desastres en 2011 en Nova Friburgo (RJ)}

Resumen: El presente análisis aborda formas en que la participación social y política para la reconstrucción de espacios afectados por catástrofes de lluvia puede tener repercusiones en las transformaciones de la relación del Poder Público con las comunidades y las políticas públicas urbanas. Se pretende presentar el conocimiento local presente en disputas territoriales y el acceso a espacios técnicos y políticas públicas para la gestión de desastres y la planificación

\footnotetext{
${ }^{1}$ Doutoranda pelo Programa de Pós-Graduação em Antropologia da Universidade Federal Fluminense. Pesquisadora do Laboratório de Estudos de Movimentos Sociais, Trabalho e Identidade (LEMSTI/UFF), grupo de pesquisa cadastrado no CNPq. E-mail: suellentcorrea@gmail.com. ORCID: https://orcid.org/0000-0003-1498-3231.
} 
urbana. Con este fin, se presenta parte de mi investigación de tesis, que incluye el estudio de caso de la participación política de los residentes del barrio Córrego D'Antas, en Nova Friburgo (RJ), a favor de la reconstrucción de la localidad y las mejoras en los servicios, después de ser golpeado por el desastre que involucró lluvias, inundaciones y deslizamientos de tierra en enero de 2011. Habrá casos en profundidad relacionados con algunos trabajos y reuniones de revisión de planes de la ciudad en el barrio en 2014, en el contexto posterior al desastre. La participación através de la Asociación de Residentes y la activación de nuevos conocimientos en la esfera política se toman como ejemplo en este artículo, a fin de traer reflexiones sobre la afirmación de las territorialidades en contextos de desastres urbanos.

Palabras-clave: Catástrofes. Dinámica territorial. Participación comunitaria. Conocimiento local.

\section{Territorial dynamics and local knowledge around conflicts in a neighborhood in Nova Friburgo (RJ) after the 2011 disaster}

Abstract: This article analyses the ways in which social and political participation for the reconstruction of spaces affected by rain catastrophes can reverberate in the relation of the Public Power with communities and the urban public policies. The intention is to present the local knowledge in territorial disputes and in the access to technical spaces and public policies for disaster management and urban planning - so part of my masters research is presented, involving the case study of the political participation of residents of Córrego D'Antas neighborhood, in Nova Friburgo (RJ), in favor of the locality reconstruction and the services improvements, after being hit by the disaster involving rainfall, floods and landslides in 2011. Some cases will be addressed, as works and review meetings with City Hall in the neighborhood in 2014. The participation through the residents association in the neighborhood and the activation of new knowledges in the political sphere are taken as examples in this article, in order to bring reflections on the affirmation of territorialities in urban disaster contexts.

Keywords: Disasters. Territorial dynamics. Community Participation. Local Knowledge.

\section{Introdução}

Este artigo tem por objetivo inicial apresentar parte da organização e do engajamento político de um grupo de pessoas através de uma associação de moradores do bairro, em torno de conflitos ligados à gestão de desastres, a partir da catástrofe das chuvas que atingiram a Região Serrana do estado do Rio de Janeiro em 2011.

Junto a esta apresentação serão analisadas formas em que a participação social e política pela reconstrução de espaços atingidos por catástrofes de chuvas podem repercutir nas transformações da relação do Poder Público com comunidades e nas políticas públicas urbanas.

Para isso serão delineados acionamentos e afirmações de saberes locais durante reuniões dos moradores com representantes de uma obra de contenção feita no bairro, além dos discursos e visões dos moradores sobre obras e projetos. 
Dossiê | Dinâmicas Territoriais e Saber Local em Torno de Conflitos em um Bairro Atingido pelo Desastre de 2011 em Nova Friburgo (RJ) (CORREA, Maria Suellen Timoteo)

A partir do processo de Revisão do Plano Diretor na cidade, seguirão à presente análise reuniões no bairro e os conflitos de interesses verbalizados durante e após as mesmas.

Esta breve apresentação tem origem na etnografia baseada nessa participação, apresentada como dissertação de mestrado em Antropologia (CORREA, 2015). Este trabalho foi produzido a partir da pesquisa de campo feita no bairro Córrego D’Antas, em Nova Friburgo (RJ), ao longo de 2014, junto aos moradores que participavam direta e indiretamente da Associação de Moradores. Foi priorizado o método etnográfico da observação participante, a partir do acompanhamento e da participação de ações promovidas pela instituição no bairro (como reuniões, encontros e ações da entidade), além de entrevistas com moradores, tanto membros gestores da Associação, quanto os que participavam das reuniões, assembleias e eventos.

Cabe destacar que o desastre neste trabalho é tomado a partir de uma perspectiva da sua desnaturalização, que aponta a sua relação com uma construção social dos riscos (VALÊNCIO, 2009, VALÊNCIO et al, 2004), ligada à estrutura social, que define esses riscos a partir de fatores como a ocupação de um território, por exemplo (VALÊNCIO et al, 2004, p. 73-74).

Essa discussão também considera que há um padrão histórico de vulnerabilidade (ACOSTA, 2004, 2008), relacionado, por exemplo, à infraestrutura, à ideologia dominante, à organização sociopolítica, aos sistemas de produção e de distribuição existentes (ACOSTA, 2004, p. 130), dentre outros.

A partir dessa desnaturalização, desastres também podem ser entendidos para além de uma relação de "causa e efeito", tendo uma continuidade e existência na própria relação que as pessoas estabelecem com esses eventos, desde uma preparação, ou a forma como dão sentido aos acontecimentos e mudanças, até a maneira como agem posteriormente para lidar com os efeitos desastrosos.

Um desastre, portanto, é um processo temporal (TADDEI 2015, p. 316), relativo, ligado a variáveis (além das naturais), sociais, políticas e simbólicas. Sua duração e a extensão dos impactos estão, sobretudo, ligadas a fatores condicionados ao grau de vulnerabilidades e de resiliências. O desastre de 2011, portanto, era ainda um processo vivenciado por moradores no Córrego D'Antas em 2014. 
Dossiê | Dinâmicas Territoriais e Saber Local em Torno de Conflitos em um Bairro Atingido pelo Desastre de 2011 em Nova Friburgo (RJ) (CORREA, Maria Suellen Timoteo)

\section{Conflitos e saberes nas obras}

Uma primeira situação que pode apresentar o acionamento de saberes locais em meio a conflitos de interesses entre Poder Público e moradores é o caso das obras das pedras do bairro.

Por volta de cinco meses após o desastre, depois da remessa de verbas dos governos Federal e Estadual para a cidade, foram aprovadas cinco grandes obras para Nova Friburgo e uma delas contemplava o bairro Córrego D’Antas. Seus moradores, através da sua associação, souberam que a obra seria direcionada a uma localidade mais afastada, numa área onde havia um "condomínio de luxo" - conforme o relato de um dos moradores (CORREA, 2015, p. 83).

Os moradores e a associação, depois de tomarem conhecimento da tal empreitada, iniciaram uma "luta" que levou meses para direcionar a obra para uma região mais populosa no bairro, onde, além de possuir mais moradores, havia mais demanda e necessidade de reconstrução por conta do desastre, por ser uma "área de risco".

Depois de abaixo-assinados, ofícios, reuniões e reivindicações, desde 2011, o Córrego D'Antas foi contemplado com o que viria a ser a "maior" obra de contenção do estado em 2013. Ela foi feita na parte central do bairro, no lado das pedras e, de fato, foi uma grandiosa obra, envolvendo "pontos de drenagem, canais de gabião, caneletas, pontos de contenção, com mureta chumbada e aplicação de contrafortes", dentre outras ações, conforme explicado por um dos engenheiros da empresa que a executava em 2014 (CORREA, 2015, p. 85).

“Obra de contenção do Córrego Dantas será a maior do estado e custará R\$ 43 milhões. Dois anos e oito meses após a tragédia climática de 2011 surge uma luz no fim do túnel para os milhares de moradores que ainda residem em área de grande risco na parte alta do Córrego Dantas: a Secretaria Estadual de Obras (SEOBRAS), conforme antecipou o colunista Giuseppe Massimo na edição de sábado, 7, marcou para o dia 9 de outubro a licitação da obra de contenção do bairro, tida como a maior do Estado do Rio, orçada em R\$ 43,900,139,42" (A VOZ DA SERRA, 11 set. 2013). 
Dossiê | Dinâmicas Territoriais e Saber Local em Torno de Conflitos em um Bairro Atingido pelo Desastre de 2011 em Nova Friburgo (RJ) (CORREA, Maria Suellen Timoteo)

Para membros da Associação de Moradores, a mudança da área contemplada com a obra, do condomínio para as pedras, deveu-se ao envolvimento dos moradores. O bairro obteve outras conquistas, antecedidas de ação e organização dos moradores (CORREA, 2015).

Essa área onde foi realizada a obra compreende uma parte do bairro (ao lado de uma RJ que corta a localidade), em uma encosta rochosa com dezenas de casas abaixo. Em 2011, pedras, lama e terra rolaram morro abaixo nesse lado do bairro, e muitas pessoas continuaram morando ali depois do ocorrido, aguardando ações de contenção nas pedras, com medo e preocupação.

Em 2013, antes do início das obras, foi divulgada uma nota sobre o rolamento de uma pedra no bairro, explicitando essa preocupação com a demora na resolução daquele problema:

\begin{abstract}
"Na manhã de quarta-feira, 4 moradores do bairro Córrego Dantas se assustaram com o comentário nas ruas de que uma pedra teria rolado de uma encosta do bairro. (...) O vice-presidente da associação de moradores do Córrego Dantas, Edmo, alertou quanto à necessidade de obras de contenção urgentes no local. Por enquanto, nem a licitação para escolha da empreiteira que vai conter a encosta tem data prevista para ser realizada, embora um projeto de execução do serviço já tenha sido concluído e encaminhado ao Tribunal de Contas do Estado, segundo a associação de moradores do bairro. 'Os moradores, é claro, ficam com medo, pois o risco de outras pedras rolarem existe em qualquer época do ano, não só nas chuvas. As pedras estão todas soltas. Por sorte, a maioria dos moradores deixou as casas com medo. Não se sabe quando uma pedra dessas poderá rolar e qual a velocidade que ela vai parar embaixo, justamente na direção das casas', observa Edmo" (A VOZ DA SERRA, 06 set. 2013).
\end{abstract}

Como se pode perceber, a obra de contenção das pedras era um assunto de caráter urgente na discussão e na lista de demandas do bairro, visto que constantemente os moradores viviam na dúvida sobre novos rolamentos e da existência de necessidade de saírem de suas casas. No entanto, a empreitada começou mais de um ano depois das chuvas de janeiro de 2011. 
Imagem 1: Foto da vista para as pedras

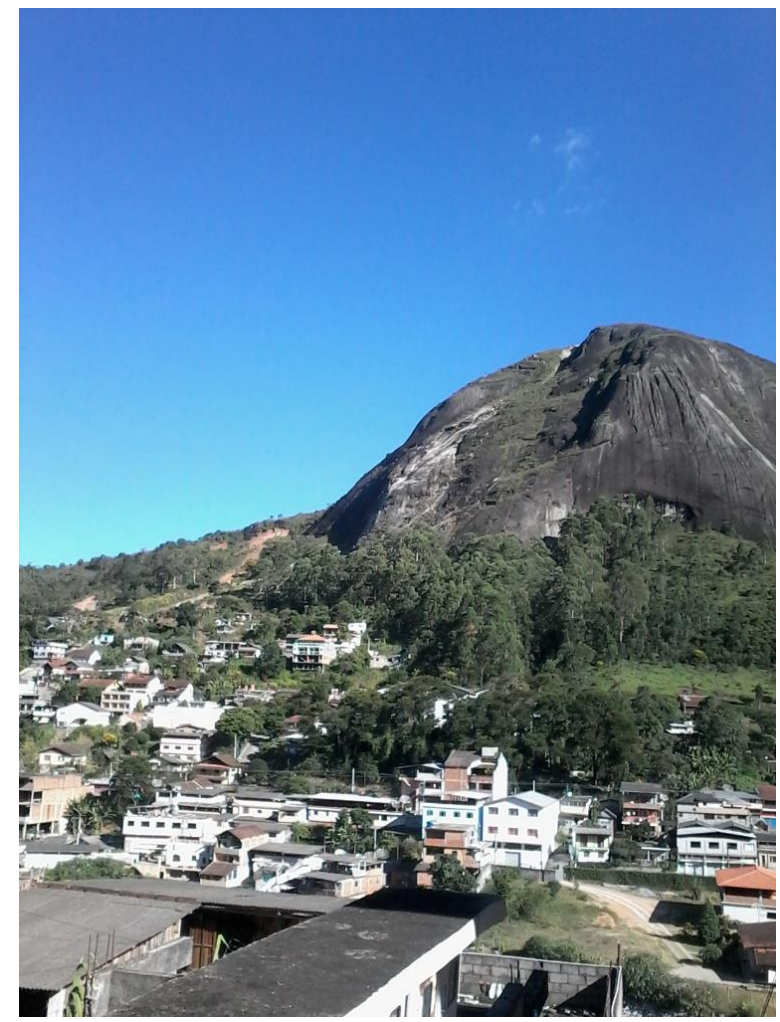

Fonte: Acervo pessoal (fevereiro/ 2014).

Cabe destacar que a preocupação vinha atrelada ao conhecimento sobre aquela parte do bairro por parte de alguns moradores, sobretudo os residentes mais antigos e/ou que lidavam com obras e com construção civil.

Durante uma reunião na Associação de Moradores em que estive presente em 2014, a principal pauta era justamente o acompanhamento da obra em andamento, visto que os moradores reclamavam que não tinham informações sobre o que estava sendo feito nas pedras, no que consistiria a obra, se durante e depois dela haveria a necessidade de desapropriar mais casas e retirar mais famílias na parte do morro abaixo das pedras.

Então a associação convocou uma reunião com os representantes dos governos local e estadual, juntamente com representantes da empresa para saber mais sobre a obra e repassar as informações para outros moradores (CORREA, 2015, p. 85).

Nessa reunião que antecedeu o encontro com os representantes, moradores criticavam a falta de diálogo sobre as obras no bairro. Um dos moradores, profissional da área de construção civil, citou o CAO, Comitê de Acompanhamento de Obras, ligado 
Dossiê | Dinâmicas Territoriais e Saber Local em Torno de Conflitos em um Bairro Atingido pelo Desastre de 2011 em Nova Friburgo (RJ) (CORREA, Maria Suellen Timoteo)

ao INEA - Instituto Estadual do Ambiente. Para ele, apesar do comitê ter sido criado para que os moradores pudessem acompanhar as obras no seu bairro, como uma tentativa de aproximação, na prática não era fácil para os moradores participarem, pois muitas vezes alguns profissionais não levavam a sério seus conhecimentos.

Em concordância com a afirmação anterior, outro morador citou o Estatuto da Cidade $^{2}$, como uma garantia da participação dos moradores, mas que não era totalmente respeitado. Em uma lista de demandas feita pela associação à época, foi apresentado que a opinião da comunidade não era aceita nas reuniões propostas e os moradores não tinham acesso à planta baixa do local da obra (Ibidem, p. 85).

A reunião convocada para tratar somente da obra e suas consequências ocorreu um tempo depois. Participaram desse encontro os representantes da empresa, como o engenheiro de campo, responsável pela obra, e o gestor de contratos da empresa. Além destes, o gestor social e o superintendente de obras do estado do Rio de Janeiro também participaram da reunião, juntamente ao coronel secretário da Defesa Civil e aos moradores.

A reunião começou com uma apresentação sobre a obra, seu planejamento e o que já estava sendo feito. $O$ engenheiro da empresa explicava com slides apontando para imagens da pedra, como e onde seria feita cada ação nas pedras. Explicou sobre como estabilizariam a encosta, usando pontos de drenagem, canais de gabião, caneletas, pontos de contenção, com mureta chumbada e aplicação de contrafortes. Usou muitos termos técnicos, compreendidos pelos moradores e em muitos momentos questionados por alguns (CORREA, 2015, p. 85).

Ao longo da explanação, alguns moradores faziam questionamentos, mostrando conhecimentos que tinham sobre o bairro - dizendo o nome dos locais apontados no mapa pelo engenheiro, até mesmo corrigindo-o em relação a algumas localidades - e sobre questões técnicas, como o diâmetro das caneletas (se era suficiente), a largura da mureta, se a mesma era chumbada, entre outros requerimentos.

O conhecimento apresentado pelos moradores sobre o bairro e a experiência sobre lugares e características das pedras, por exemplo, além da forma como questionavam e usavam os termos técnicos lançados pelos engenheiros davam uma

\footnotetext{
${ }^{2}$ Lei 10.257 de 2011, disponível em http://www.planalto.gov.br/ccivil 03/leis/leis 2001//10257.htm (acessado em 04/06/2019).
} 
Dossiê | Dinâmicas Territoriais e Saber Local em Torno de Conflitos em um Bairro Atingido pelo Desastre de $2011 \mathrm{em}$ Nova Friburgo (RJ) (CORREA, Maria Suellen Timoteo)

propriedade aos moradores não questionada pelos representantes presentes na reunião, mesmo quando interrogados e avaliados.

Foi, portanto, a proximidade estabelecida entre os moradores, mais os agenciamentos relacionados aos seus saberes e experiências no bairro que prevaleceram e deram o direcionamento daquela reunião. Algumas críticas foram registradas e prontificadas à revisão pelo engenheiro. Outras não foram respondidas objetivamente. Sobre a quantidade de determinados materiais, o gestor de contratos da empresa alegou que o quantitativo de contrafortes poderia mudar, para mais ou menos, devido a outros fatores, como as erosões e o caráter dinâmico das pedras.

Um morador perguntou sobre a possibilidade de intervenção e evacuação na região do morro abaixo das pedras, uma dúvida que vinha angustiando muitos moradores. Além dessa imprecisão, muitos moradores que tiveram suas casas interditadas aguardavam notícias da obra para saber se poderiam retornar às casas ou continuariam com processos de indenização e de aluguel social.

O gestor de contratos e o engenheiro afirmaram existir uma previsão de não interdição, mas que essa decisão caberia ao Estado e à Defesa Civil, ao que o Coronel da Defesa Civil afirmou com a cabeça em concordância. No entanto, depois acrescentou que a responsabilidade seria de órgãos conselheiros, os quais a Defesa Civil acionava para essa averiguação. O representante da Defesa Civil disse que a mesma não agia sozinha, por isso a dificuldade em dar uma resposta precisa (CORREA, 2015, p. 86).

Na reunião pude notar que muitas respostas não foram suficientemente precisas e esclarecedoras para os moradores, que insistiram em refazer e reformular algumas perguntas. Pude confirmar isso posteriormente em uma reunião da associação, a partir das falas de alguns moradores, avaliando como positiva a iniciativa da reunião entre os moradores e os responsáveis pela obra, mas como um esclarecimento ainda inicial.

Então os moradores encaminharam mais reuniões esporádicas com os representantes e, a pedido do presidente, um convite para a ida do engenheiro à assembleia, para que pudessem esclarecer informações para a comunidade.

$\mathrm{Na}$ assembleia seguinte, foi lido o relatório da reunião sobre a obra e alguns moradores, sobretudo os que tinham formação e experiência com obras, demonstraram preocupação em relação à espessura das galerias de drenagens. Segundo os mesmos, a espessura da galeria prevista para ter $1,20 \mathrm{~m}$ por $1,20 \mathrm{~m}$ era muito estreita, e poderia 
Dossiê | Dinâmicas Territoriais e Saber Local em Torno de Conflitos em um Bairro Atingido pelo Desastre de $2011 \mathrm{em}$ Nova Friburgo (RJ) (CORREA, Maria Suellen Timoteo)

causar problemas em ocasiões de fortes chuvas. Como consta na ata da assembleia realizada em 04 de abril de 2014, foram vários os argumentos apresentados em plenária contrariando o tamanho da galeria:

“[...] a situação da principal subida de acesso ao bairro Braunes que apresenta problemas que já são notórios "quando tem um maior volume d'água de chuva, estoura (água) para todo lado"; o Senhor Edmo relata que as manilhas que atravessam o subsolo da RJ 130 já tem esta espessura aproximada de 1,20 m e que atualmente não comporta volumes maiores de água da chuva; Chamou-se atenção também para o fato do projeto inicial, produzido para a licitação e elaborado sob a coordenação do Engenheiro da UERJ, Sr. Feijó, previa a espessura de 3 metros de altura por 3 metros de largura, tendo sido, neste momento, reduzido para aproximadamente menos de um terço do tamanho original; Outro argumento exposto trata-se das anunciadas e notórias mudanças climáticas, em curso no planeta, que indicam o aumento de precipitação pluviométrica, denotando que, em se tratando de uma obra de tamanha envergadura, deveria se trabalhar com projeções à longo prazo, no caso, que as galerias sejam construídas com margem de segurança para suportar eventos climáticos futuros" (ASSOCIAÇÃO DE MORADORES DO CÓRREGO D’ANTAS, 2014).

Ainda sobre a obra das pedras, o presidente da associação informou aos moradores que havia feito um convite para que o engenheiro representante da obra comparecesse àquela assembleia, a fim de expor à comunidade o projeto da obra, mas não obtivera resposta do mesmo.

\section{O Plano Diretor e a organização comunitária}

Outra situação evidenciando os conflitos de interesses entre moradores e a Prefeitura foi o processo de revisão do Plano Diretor da cidade. Nas reuniões apresentadas aos moradores no bairro, era evidente o interesse da gestão pública em manter regiões cada vez maiores para a preservação ambiental (em consonância com um projeto do INEA de parque fluvial, margeando toda uma região do Córrego que já vinha passando por desapropriações e demolições de imóveis) e para a expansão industrial - já que o bairro no Plano Diretor antes da revisão tinha áreas consideradas de 
Dossiê | Dinâmicas Territoriais e Saber Local em Torno de Conflitos em um Bairro Atingido pelo Desastre de $2011 \mathrm{em}$ Nova Friburgo (RJ) (CORREA, Maria Suellen Timoteo)

expansão industrial e, com o desastre e as desapropriações, poderia comportar uma área maior para este $\mathrm{fim}^{3}$.

A SEMMADUS, a então Secretaria de Meio Ambiente e Desenvolvimento Urbano Sustentável da cidade, no processo de Revisão do Plano Diretor de Nova Friburgo, convocou reuniões em dezenas de bairros para levarem sua proposta de revisão para os moradores, sobretudo no que dizia respeito às localidades em questão.

No Córrego D’Antas, antes da reunião indicada pela Prefeitura, os moradores, através da associação, se reuniram e elaboraram sua própria proposta que viria a ser solicitada no processo de Revisão do Plano Diretor para o bairro, na então reunião de revisão.

Imagem 2: Foto do cartaz de divulgação da reunião dos moradores anterior à reunião da SEMMADUS

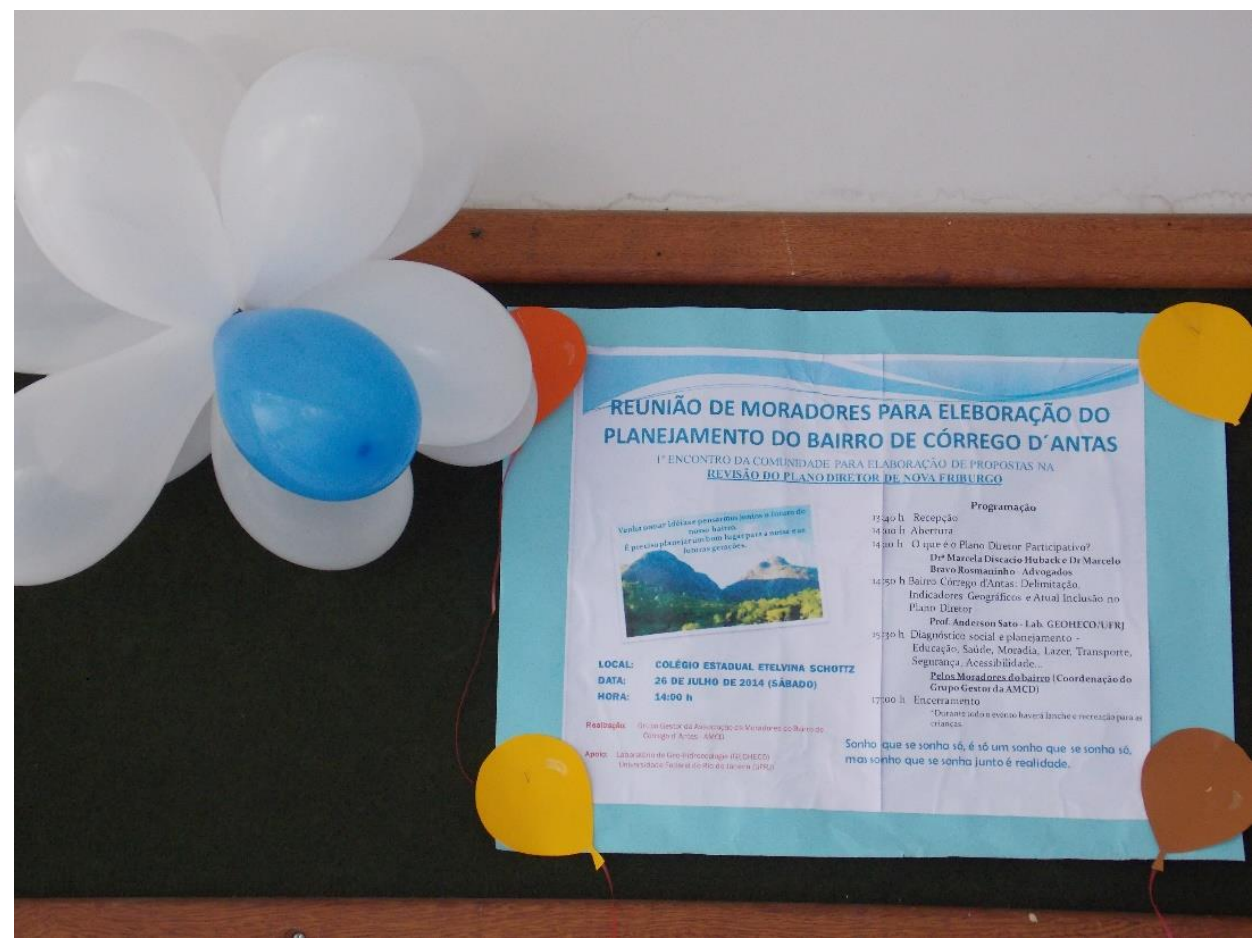

Fonte: Acervo pessoal (Julho/2014)

No dia da reunião com a SEMMADUS, além dos seus interesses, os moradores puderam apresentar algumas inconsistências e divergências no Plano Diretor. Uma

\footnotetext{
${ }^{3}$ Na dissertação descrevo mais detalhadamente as reuniões, a organização e as estratégias dos moradores para imporem seus interesses nas reuniões da revisão do Plano Diretor (CORREA, 2015).
} 
delas era a questão do aterro sanitário no bairro. Ele estava em cima de uma nascente, numa região que, segundo os moradores, não deveria ter aterro, mas ser considerada uma ZEIRA - Zona de Especial Interesse de Recuperação Ambiental. Além disso, os moradores discordavam das ZEIRAS previstas no Plano, pois encontravam-se em áreas onde já existiam moradias.

Outra reivindicação apresentada pelos moradores na reunião era a necessidade de consolidação do bairro como um bairro misto e enquanto uma ZUC (Zona Urbana Controlada). A proposta se insere no "cuidado" e no tratamento necessário para o bairro, pois as ZUC's no Plano tinham um tratamento específico de cada região, e no plano da Prefeitura não compreendia o Córrego D'Antas. Os moradores vinham percebendo, tanto na proposta do Plano Diretor - que colocava o bairro apenas como Zona de Expansão Orientada (ZEO), e não como área residencial quanto nos acontecimentos no bairro a partir do desastre, que o interesse da governamentalidade era retirar cada vez mais moradias do bairro e estimular o crescimento industrial na localidade (CORREA, 2015).

Imagem 3: Como era enquadrada a região do Córrego D’Antas, segundo o Plano Diretor em 2014

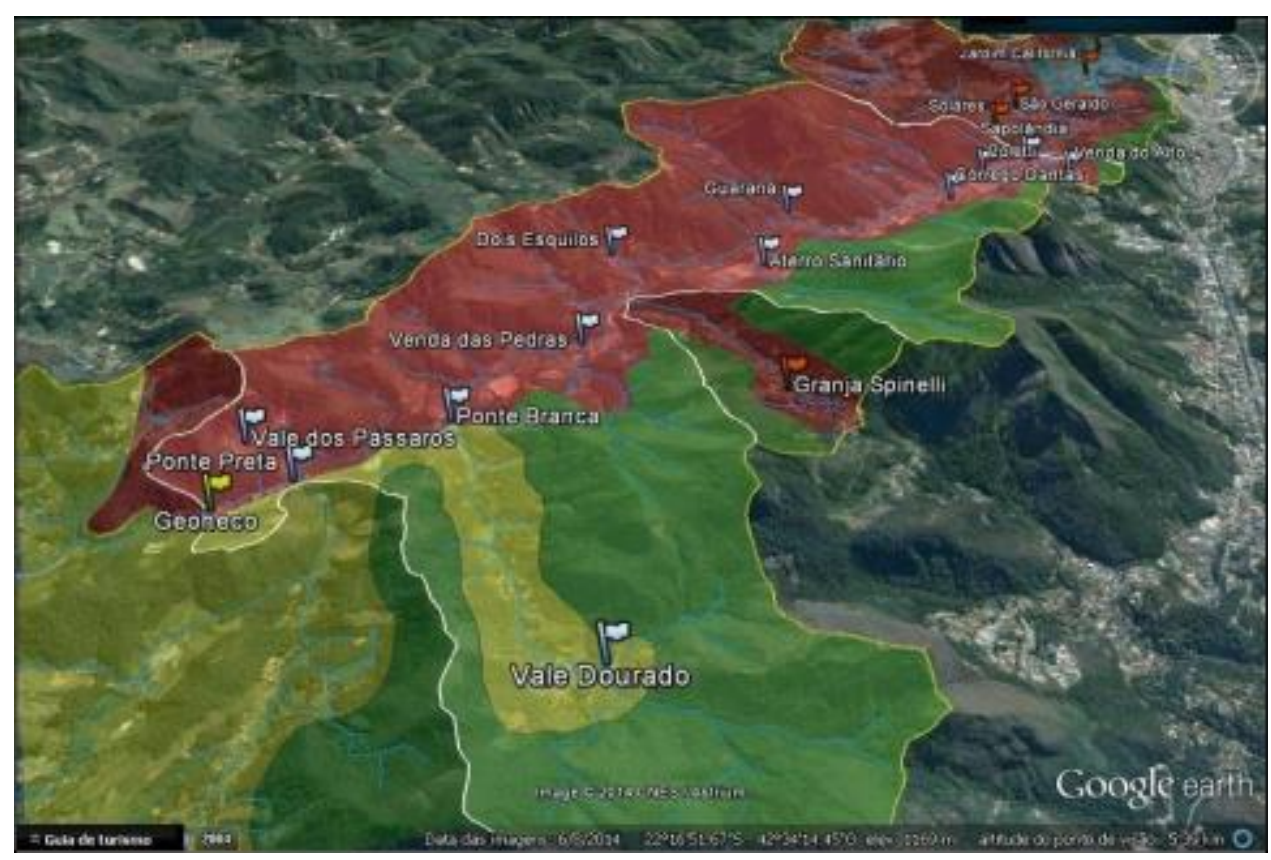

Fonte: Associação de Moradores do Córrego D’Antas (2014) 
Imagem 4: Como deveria ser compreendida a região do Córrego D’Antas a partir da Revisão do Plano Diretor, segundo os moradores

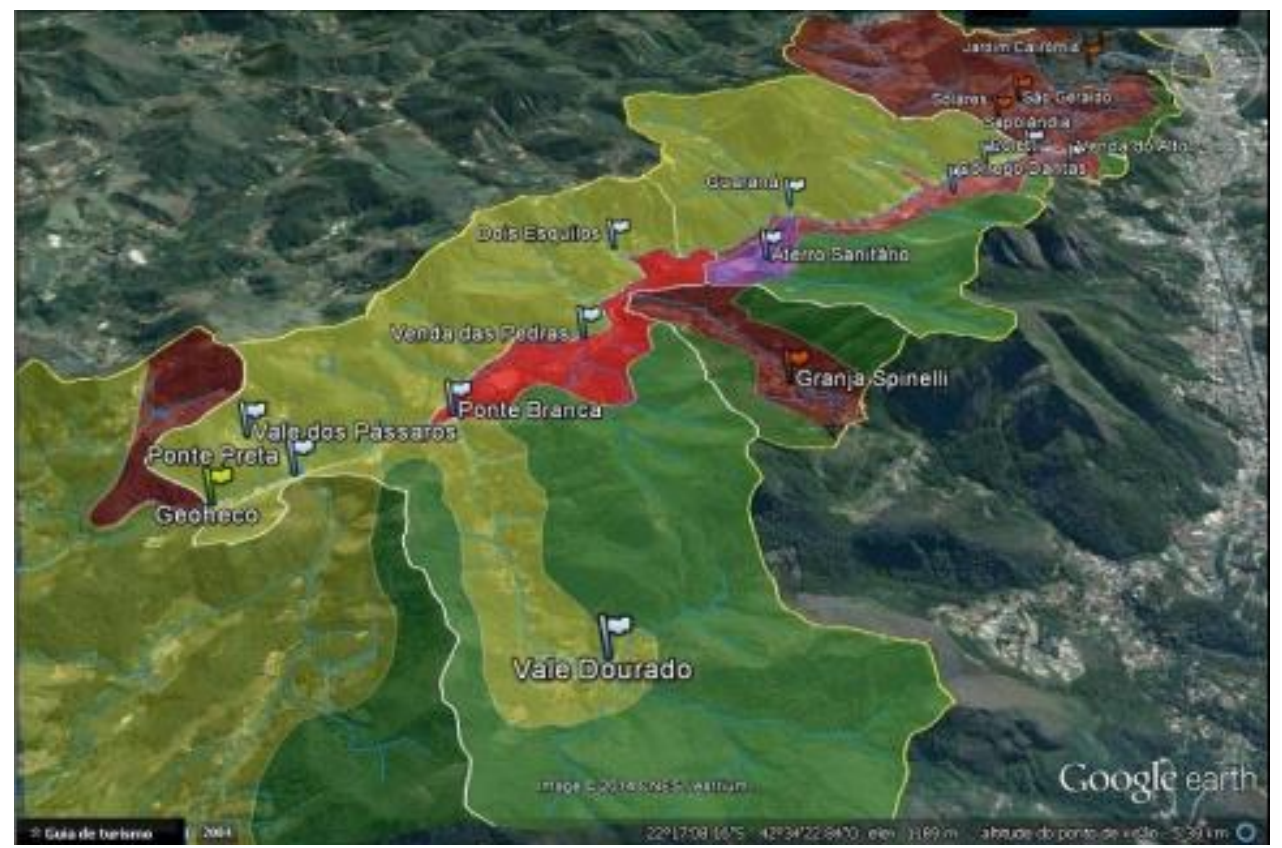

Fonte: Associação de Moradores do Córrego D’Antas (2014)

As imagens anteriores foram apresentadas pela associação na reunião com representantes da Prefeitura, de forma a dar visibilidade às diferenças de interesses entre os presentes. A região vermelha nas imagens representa a Zona de Expansão Orientada (ZEO), que deveria ser consideravelmente menor na visão dos moradores.

A área verde representa a chamada Zona de Especial Interesse Ambiental (ZEIA), não havendo grandes alterações entre as propostas. E a amarela, a Zona de Transição (ZT) que, de acordo com a resolução elaborada a partir das demandas dos moradores, deveria substituir boa parte das áreas anteriormente pertencentes à ZEO, de forma que mantivesse o interesse "social" e de "ocupação" residencial do bairro, conforme relatou o presidente da associação na reunião (CORREA, 2015, p. 120).

\section{Saberes locais e Situações de Prova}

Conforme apresentado anteriormente, algumas ações envolvendo o conhecimento dos moradores foram relevantes para o acionamento de suas intenções nos conflitos envolvendo interesses diversos entre os mesmos e o Estado. 
Dossiê | Dinâmicas Territoriais e Saber Local em Torno de Conflitos em um Bairro Atingido pelo Desastre de 2011 em Nova Friburgo (RJ) (CORREA, Maria Suellen Timoteo)

Além desses conhecimentos que foram essenciais para uma inicial organização e gestão comunitária do desastre na localidade e para o próprio engajamento, esses saberes locais também foram importantes em um segundo momento, de maneira a estarem presentes nas negociações e reivindicações dos moradores frente ao Estado e para imporem seus interesses(Ibidem, 2015).

Esses conhecimentos locais - ou saberes locais - vão além de um conhecimento específico e profissional. Segundo Renzo Taddei, "saber é algo mais do que informação, no sentido de que envolve mais do que cognição, incluindo outras dimensões da existência - algo que se pratica com o intelecto e com as demais faculdades humanas" (2015, p. 318).

Os saberes locais acionados a partir do presente estudo estão relacionados aos chamados "vínculos de proximidade", portanto, "aos modos de uso, de frequentação e de habitação do bairro" (CEFAï, 2011, p. 70). Somados a esses vínculos, os saberes locais também permearam a própria mobilização para a reconstrução do bairro e a proximidade entre os atores.

\footnotetext{
"Além disso, a definição da situação da reabilitação do bairro se apoia em saberes locais, relativos às formas de vida associativa próprias de um território, aos usos de lugares semipúblicos e públicos, às práticas de solidariedade e de ajuda mútua entre vizinhos; como também saberes referentes ao estado de deterioração dos imóveis, às necessidades de áreas livres de jogos para crianças e de espaços de integração para adultos (...)" (CEFAï, 2011, p. 82).
}

Indicações nas reuniões sobre qual o lugar entendido como mais adequado para se construir um ponto de drenagem ou qual a melhor espessura de uma caneleta na obra de contenção; ou a indicação da parte do bairro mais propícia à educação e saúde (para construção de creche e posto de saúde, por exemplo) são modelos descritos de ações empreendidas por moradores ao longo de 2014 e que dialogam com os saberes locais. São saberes que estão ligados à frequentação dos lugares, além das experiências individuais e coletivas dos atores, "de seus modos de uso dos espaços privados, semipúblicos e públicos, de suas valorizações dos lugares vividos e praticados no dia a dia, investidos de toda sorte de qualidades que escapam ao urbanista" (Ibidem, p. 82). 
Dossiê | Dinâmicas Territoriais e Saber Local em Torno de Conflitos em um Bairro Atingido pelo Desastre de $2011 \mathrm{em}$ Nova Friburgo (RJ) (CORREA, Maria Suellen Timoteo)

Os saberes locais colocam, portanto, os moradores em condição privilegiada a respeito do conhecimento do bairro. Para os casos relacionados à obra nas pedras, apresentada anteriormente, os residentes acionaram seus conhecimentos relacionados às obras e ao bairro para confrontarem com o conhecimento técnico e burocrático de representantes do Estado e da empresa contratada.

Sobre a reunião do Plano Diretor no bairro, o conhecimento que os moradores tinham uns sobre os outros e o engajamento a partir da associação permitiu que os mesmos fizessem um planejamento anterior à presença da Prefeitura no bairro, para que pudessem demonstrar de forma organizada e enfática os seus requerimentos no processo de Revisão do Plano Diretor.

As reuniões no bairro envolvendo moradores e representantes do Poder Público, tanto a solicitada pelos moradores para tratar das obras das pedras quanto a reunião proposta pela Prefeitura para a Revisão do Plano Diretor foram oportunidades em que os moradores puderam apresentar suas demandas e saberes, configurando uma situação de prova de "consulta e deliberação", nos termos de Daniel Cefaï (2011).

As situações de prova são situações que organizam as experiências dos protagonistas em uma cena pública (CEFAï, 2011, p. 94). No caso das situações de prova de consulta e deliberação, como em reuniões públicas, "nas quais se opõem de um lado, discursos de políticos e de especialistas e, de outro lado, discursos de associados e de moradores" (Ibidem, p. 94), os conflitos são evidenciados e as disputas se desenrolam.

Nesses exemplos descritos na presente produção, os moradores puderam impulsionar e tornar públicas suas ações e intenções, dando o direcionamento das cenas, deixando a gestão pública em situação defensiva e correspondente aos interesses dos moradores, em alguns momentos.

\section{Considerações finais}

A participação através da Associação de Moradores do bairro e o acionamento de saberes nessas situações descritas acima foram tomados como exemplos neste artigo, de forma a trazerem reflexões sobre a afirmação de territorialidades em contextos de desastres urbanos. 
Dossiê | Dinâmicas Territoriais e Saber Local em Torno de Conflitos em um Bairro Atingido pelo Desastre de 2011 em Nova Friburgo (RJ) (CORREA, Maria Suellen Timoteo)

Para esta produção, portanto, foi possível apresentar as ações coletivas locais e os saberes presentes nessa participação política perpassando o desenrolar do processo catastrófico, bem como as relações com o território e com as políticas de gestão de desastre e de planejamento urbano.

De um lado, portanto, o Estado acionava a proporção do desastre e reinventava suas práticas (indenizações, desapropriações, revisão do Plano Diretor) para garantir seu projeto de expansão industrial do bairro. Tanto a municipalidade quanto o governo estadual (INEA) deram sentido aos seus projetos de retirada dos moradores para outra área da cidade, construindo um complexo habitacional para os indenizados do desastre (CORREA, 2015).

De outro lado, os moradores se associavam, acionavam a destruição e os problemas a partir do desastre para fins diversos, como a reivindicação de direitos, da escuta de seus saberes e a cobrança de ações para a reconstrução do bairro e a manutenção nele. As afirmações e sentidos atribuídos ao desastre no bairro, portanto, perpassaram pelos saberes locais e pelo engajamento dos moradores.

Esta disputa de sentidos em torno das dinâmicas territoriais e das reconfigurações urbanas pode fornecer pistas de como o Estado opera e como as resistências que se opõem a essas governamentalidades são complexas, heterogêneas e em constante transformação.

A produção, ao final, pôde dar subsídios para algumas reflexões e problematizações acerca dos desastres, da gestão pública, da participação comunitária no processo de reconstrução, sobretudo mostrando que esta disputa de sentidos em torno das dinâmicas territoriais e das reconfigurações urbanas foi relevante para compreender a complexidade em torno de conflitos socioambientais.

\section{Referências}

ACOSTA, Virginia G. Historia y desastres en América Latina, III. coord. Virginia Acosta. México: Centro de Investigaciones y Estudios Superiores en Antropología Social/Red de Estudios Sociales en Prevención de Desastres en América Latina, 2008, $358 \mathrm{p}$.

. La Perspectiva Histórica em La Antropologia Del Riesgo y del Desastre. Acercamientos metodológicos. Relaciones, XXV (97), 2004, 19 p. 
CEFAI, Daniel. Como uma Associação Nasce para o Público: vínculos locais e arena pública em torno da associação La Bellevilleuse em Paris In CEFAI, D., Mello, M. A. S., MOTA, F. R., VEIGA, F. B. Arenas Públicas: por uma etnografia da vida associativa. Niterói: Editora da Universidade Federal Fluminense, 2011, p. 67- 102.

CORREA, Maria Suellen Timoteo. A Política no Desastre em Nova Friburgo/RJ: uma análise da participação de moradores na reconstrução do bairro Córrego D'Antas. 2015. Dissertação de Mestrado em Antropologia. Universidade Federal Fluminense. Niterói, 2015, 189 p.

MORADORES assustados com pedra que teria rolado de encosta sem contenção. Nova Friburgo: A Voz da Serra, 06 set. 2013.

OBRA de contenção do Córrego Dantas será a maior do estado e custará R\$ 43 milhões. Nova Friburgo: A Voz da Serra, 11 set. 2013

TADDEI, Renzo. O lugar do saber local (sobre ambiente e desastres). In: SIQUEIRA, A., VALENCIO, N., SIENA, M., MALAGOLI, M. A. (Org.). Riscos de desastres relacionados à água: aplicabilidade de bases conceituais das ciências humanas e sociais para a análise de casos concretos. São Carlos: Rima Editora, 2015, 16 p.

VALÊNCIO, N., PRATER, C., CAMPOS, P. F. C., TRIVELIN, L. M., SIENA, M., EVANGELISTA, J., CATÓIA, C., MARCHEZINI, V., CRISTOFANI, G., TAGLIAFERRO, M., BARBOSA, A. R., PAGANELLI, J., PAVAN, B. A produção social do desastre: dimensões territoriais e político institucionais da vulnerabilidade das cidades brasileiras frente às chuvas. Teoria e Pesquisa, v.44-45, 2004, p. 67-115.

VALÊNCIO, Norma. Sociologia dos desastres: construção, interfaces e perspectiva no Brasil. São Carlos: RiMa Editora, 2009, 208 p. 